\title{
POSTEROLATERAL KNEE INSTABILITY: AN ALTERNATIVE PROPOSAL FOR SURGICAL TREATMENT
}

César Teruyuki Kawano, Rosalvo Zósimo Bispo Jr., Marcus Guilherme de Oliveira, Alexandre Takayuki Soejima, Stella de Barros Apostolopoulos

\section{INTRODUCTION}

In spite of the low incidence of posterolateral instability of the knee, its recognition has become highly important, because lack of diagnosis leads to severe sequelae, mainly when associated with anterior and/or posterior cruciate ligament injuries, evolving to varus deformity, hyperextension, and failure of the primary ligament reconstructions of this joint in those cases where they are performed. ${ }^{1-4}$

Observing the evolution of reconstructive surgeries for knee ligament injuries, we found that improvement is still needed, since some of the performed procedures show sequelae, and we noticed the failure of primary reconstructions secondary to lack of early recognition of other peripheral failures such as posterolateral corner instability.

In the knee with a chronically affected posterolateral corner, the main objective is to restore the biomechanical stability so that the patient can attain the same level of activity enjoyed before the injury. However, it is very difficult to reach this desirable level, mainly because these injuries are very complex.

A variety of surgical techniques have been described, although often with moderate results. Several studies on anatomical structures to be repaired, plus the determination of dynamic isometric points ${ }^{5}$ on the femur and head of the fibula, promote an increased opportunity to obtain stable knees.

There is no consensus on the best technique to use for repairing injured lateral and posterolateral structures of the knee, since this instability involves many anatomical factors as well as the determination of static and dynamic isometric points to be adopted for these reconstructions.

CEMKA - Kawano Policlinic, Sao Paulo, Brazil.

UNIPE - University Center of Joao Pessoa, Paraiba, Brazil

Email: zosimo_jr@yahoo.com.br

\section{SURGICAL TECHNIQUE}

We indicate the reconstruction of chronic posterolateral corner injury in the presence of a varus opening larger than $5 \mathrm{~mm}$, a tibial external rotation greater than approximately 6 degrees when compared with the contralateral knee, associated with hyperextension. ${ }^{6}$

Once the patient is under anesthesia, we perform a propedeutic study for the evaluation of the knee to make a final check for ligament instabilities, because at that moment the patient is totally relaxed, which greatly facilitates the physical examination.

The curvilinear incision is started with the flexed knee, beginning in the proximal and lateral region of the tibia, between Gerdy's tubercle and the fibular head, and extending proximally and linearly on the lateral face of the thigh for approximately $15 \mathrm{~cm}$ (Figure 1). Then the skin and the hypodermic layer are opened to expose the iliotibial tract and the Biceps Femoris muscle tendon. A blunt dissection of the fibular nerve is performed in the region of the fibu-

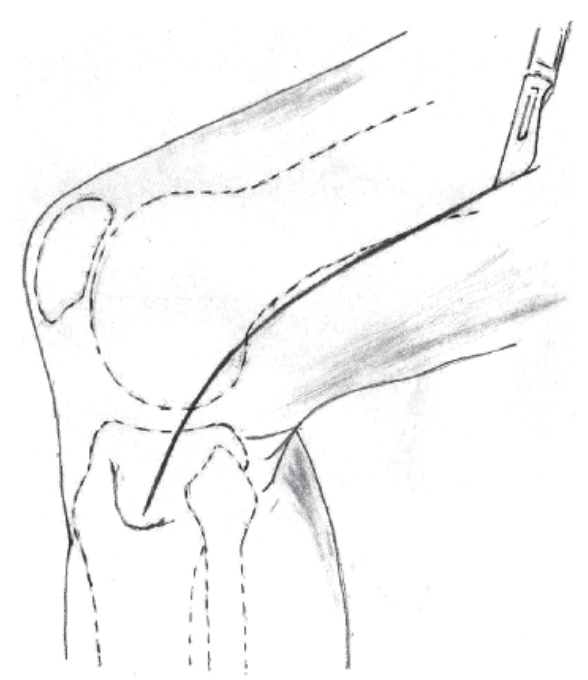

Figure 1 - Schematic drawing showing skin incision in the lateral face of the knee and the distal third of the thigh. 


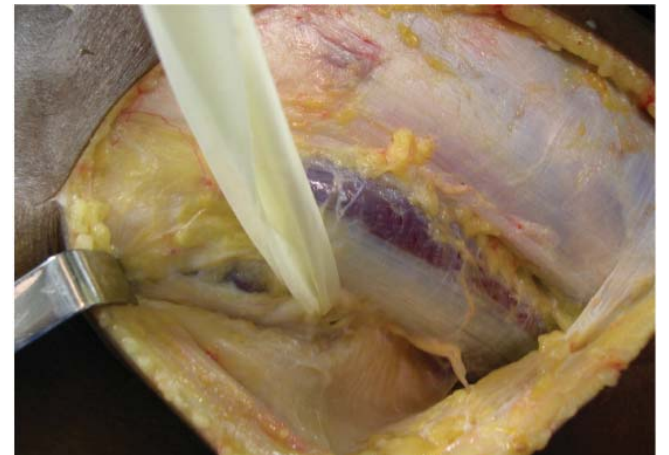

Figure 2 - Exposure of the iliotibial tract and femoral biceps muscle. Note the identification and isolation of the fibular nerve.

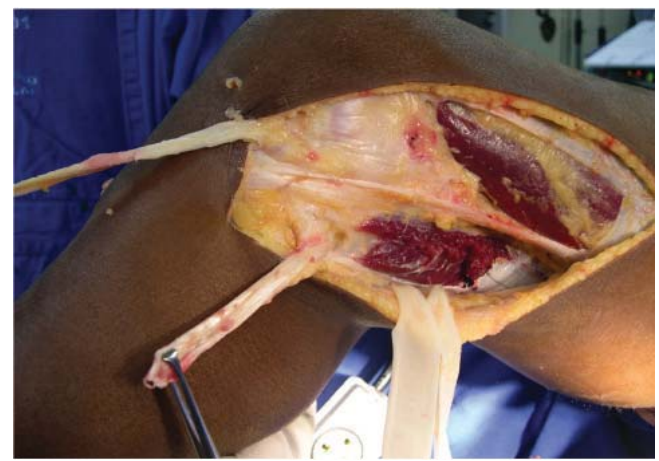

Figure 3 - Graft preparation. Above, release of iliotibial tract. Below, removal of femoral biceps muscle tendon.

lar head, extending under the biceps muscle (Figure 2).

The next stage includes the preparation of the grafts to be used (Figure 3). A 14-cm long and 3-cm wide incision is made in the medial portion of the iliotibial tract proximal to Gerdy's tubercle: the distal end remains attached to the tubercle, with release of the proximal portion (Figure 4). Three centimeters of the proximal end of the incision are basted with \#1 Vicryl ${ }^{\circledR}$ absorbable polyglycolic suture, and the rest of the fascia is divided at its median portion, the width of which is $1.5 \mathrm{~cm}$, resulting in 2 fasciculi, with the distal portion still attached to Gerdy's tubercle.

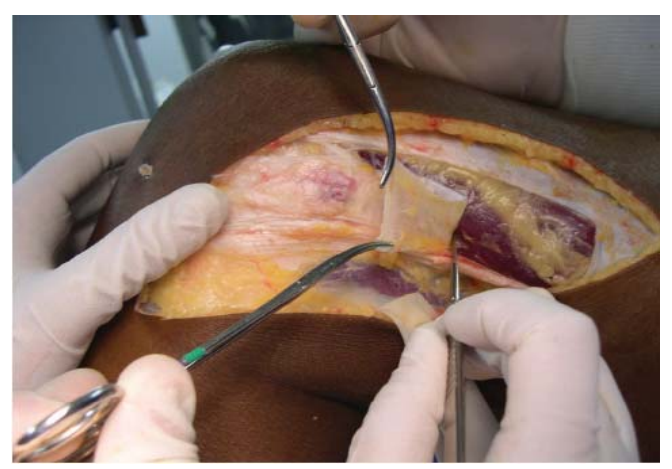

Figure 4 - Division of an iliotibial tract graft. These two portions will be responsible for the reconstruction of the popliteal tendon and popliteal fibular ligament.
Then we release one end of one of the fasciculi. These two portions are responsible for the reconstruction of the popliteal tendon and the popliteofibular ligament.

The graft to be used to repair the fibular collateral ligament is obtained by extracting two thirds of the biceps muscle tendon, which remains fixed to the fibula, with a 7-cm proximal dissection. Three centimeters of the proximal end of the graft are carefully released and sutured with \#1 Vicryl ${ }^{\circledR}$ (Figure 5).

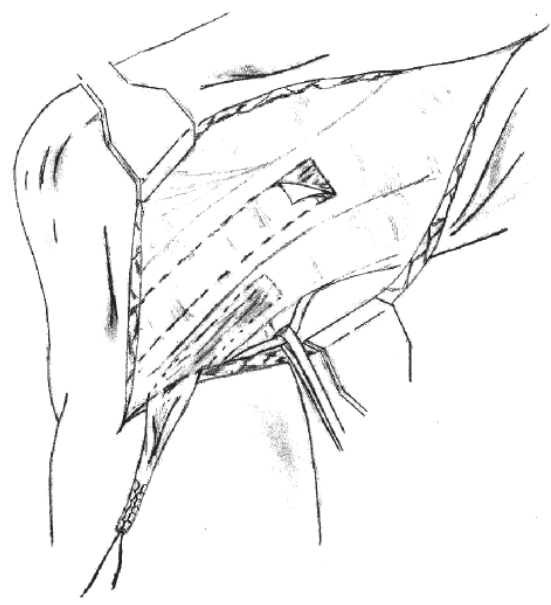

Figure 5 - Schematic drawing. Below, note the removal of femoral biceps tendon muscle to be used to repair the fibular collateral ligament.

A blunt dissection is performed between the biceps muscle tendon and the iliotibial tract and under the lateral gastrocnemial muscle head, with exposure of the posterolateral corner of the tibia.

Preparation for drilling the tunnel with an 8-mm bit for passage of the graft to reconstruct the popliteal muscle tendon starts in the tibia by placing a metal guide wire in the anterolateral proximal region, immediately distal to Gerdy's tubercle; the wire exits in the posterolateral portion, one centimeter away from the surface of the joint, near the fibular head and below the lateral portion of the lateral gastrocnemial muscle head (Figure 6).

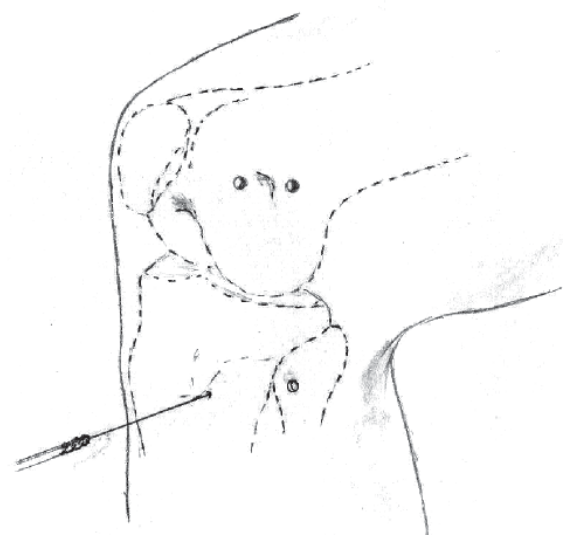

Figure 6 - Schematic drawing showing the confection of tibial, femoral and fibular tunnels. 
In the lateral femoral condyle, we drill 2 additional 8-mm tunnels near the lateral epicondyle, one in the distal anterior portion and the other in the proximal posterior portion of its most protruding area, the distance between the centers of the holes being $18 \mathrm{~mm}$ (Figure 6).

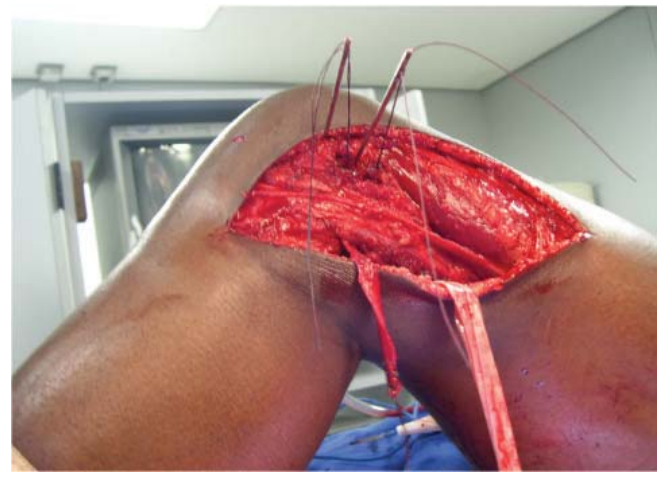

Figure 7 - Placement of guide-wires near the lateral femoral epicondyle, previous to tunnel confection.

Finally, a 5-mm transverse tunnel is drilled in the fibular head for passage of the graft to reconstruct the popliteofibular ligament (Figure 6).

The placement of the grafts starts with the fascias obtained from the iliotibial tract that is divided into 2 fasciculi, one of which remains attached to Gerdy's tubercle, through the anterior portion of the tibia, exiting at the posterolateral region (Figure 8). These two fasciculi are basted $3 \mathrm{~cm}$ in their distal ends and taken as a single bundle to the hole drilled distally and anteriorly in the femoral lateral epicondyle. The fasciculus that is released from Gerdy's tubercle is stitched in its distal end and passed through the hole drilled through the fibular head for reconstruction of the popliteofibular ligament. The portion that remains attached to the tubercle is fixed to the tibia with an interference screw (diameter, $9 \mathrm{~mm}$; length, $20 \mathrm{~mm}$ ) (Figure 9). To reconstruct the fibular collateral ligament, $3 \mathrm{~cm}$ of the distal end of the biceps tendon graft are also basted and placed in the hole drilled in the proximal and posterior region of the femoral epicondyle.

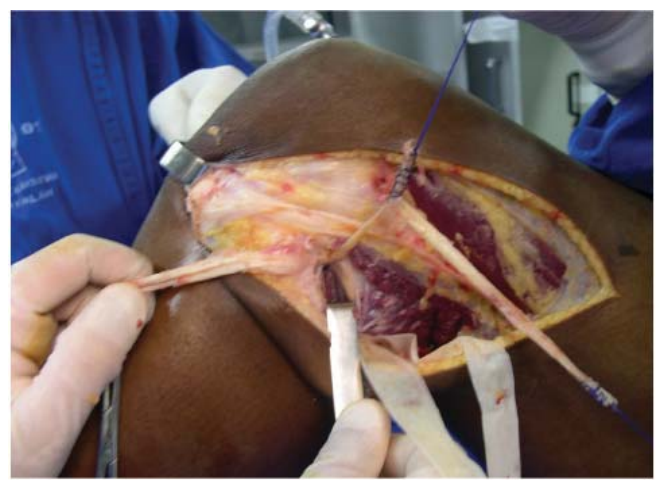

Figure 8 - Passage of the iliotibial tract graft divided into two fasciculi, through the tibial tunnel.

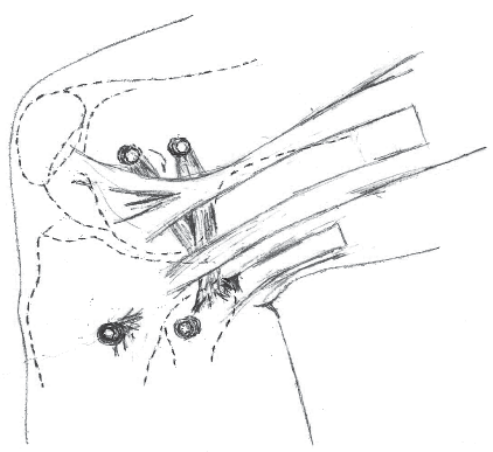

Figure 9 - Schematic drawing showing the final reconstruction of the posterolateral corner.

All grafts were passed in the region closest to the bony portion and in the deepest layer as described by Seebacher et al. ${ }^{7}$

Once the grafts are placed into the respective tunnels, pretensioning is applied with amplitude between 0 and 110 degrees for 25 cycles, with the purpose of adapting it locally and due to the viscoelasticity of the tissues; after this procedure, we fix the graft to the femoral tunnel with an interference screw (diameter, $9 \mathrm{~mm}$; length, 25 $\mathrm{mm}$ ) and to the tibial tunnel with an interference screw (diameter, $7 \mathrm{~mm}$; length, $20 \mathrm{~mm}$ ), with the knee flexed to 30 degrees, internal rotation, and valgus (Figure 9).

During the postoperative period, the lower limb is maintained immobilized for 4 weeks, followed by physical therapy.

\section{COMMENTS}

In 1982, Seebacher et $\mathrm{al}^{7}$ described the main anatomical structures of the posterolateral corner using the concept of division of the peripheral portions of the knee into 3 layers, observing that the main structures for lateral and posterolateral stabilization were located in the deepest region, and the most evidenced were the fibular collateral ligament, the fabello-fibular ligament, the popliteal muscle tendon, the arched complex, and the popliteofibular ligament.

Studies on the contribution of those structures to posterolateral and lateral stabilization static force of the knee have been conducted, ${ }^{8-10}$ suggesting that this kind of instability should be treated by reconstructing the fibular collateral ligament, the popliteal tendon with tibial attachment, and the popliteofibular ligament.

In 1988, Sidles et $\mathrm{al}^{5}$ stated that the anterior and posterior regions of the fibular head present dynamic isometricity in relation to the points proximal and distal to the femoral lateral epycondyle during knee flexion and extension motion, maintaining that it is very important to observe these factors in posterolateral corner reconstruction techniques. 
For Grade III ${ }^{11}$ acute injuries, surgical indication with sutures and reattachment of structures is the most indicated method, with good results. Various techniques have been proposed for chronic injuries, but most do not achieve satisfactory and complete stabilization of the joint.

Surgical management has been classified into procedures that partially or totally restore the anatomy and procedures that seek to stabilize by tensioning posterolateral injuries. ${ }^{12}$ Concerning the attempt to partially reconstruct the anatomy of those structures, different authors have performed the reinforcement of the fibular collateral ligament using a portion of the biceps tendon through tenodesis ${ }^{13}$ or using a portion of the tendon fixed to the femur with synthesis material. ${ }^{14-16}$

Many studies have shown the relevance of reconstructing 3 structures for posterolateral corner stabilization, namely the fibular collateral ligament, the popliteal tendon, and the popliteofibular ligament; $2,9,10,17$ according to these authors, the fibular popliteal ligament is very important, with a stabilization force similar to that of the popliteal tendon.
Another current consideration is the increasing use of homologous grafts ${ }^{18,19}$ in the reconstruction of these structures (such as the Achilles, patellar, and knee flexor tendons), due to the difficulty of obtaining a large number of autologous grafts. However, these procedures require a tissue bank for proper specimen preparation, since in these cases there is also the risk for disease transmission, rejection, and infection.

By reconstructing the 3 major stabilizing structures of the posterolateral corner (fibular collateral, popliteal tendon, and popliteofibular ligament) from autologous grafts of the biceps tendon and iliotibial tract and considering the knowledge on dynamic isometricity in the knee movement, we describe this surgical procedure with the intent of stabilizing the joint and consequently returning most patients to the activities they performed prior to the injury.

A preliminary evaluation of the utilization of this surgical procedure seems to show that it is a feasible option, although it requires longer follow-up and further evaluation of results for future conclusions.

\section{REFERENCES}

1. O`Brien SJ, Warren RF, Pavlov H, Panariello R, Wickiewicz TL. Reconstruction of the chronically insufficient anterior cruciate ligament with the central third of the patellar ligament. J Bone Joint Surg Am. 1991;73:278-86

2. LaPrade RF, Resig S, Wentorf F, Lewis JL. The effects of grade III posterolateral knee complex injuries on anterior cruciate ligament graft force. A biomechanical analysis. Am J Sports Med. 1999;27:469-75.

3. Harner CD, Vogrin TM, Hoher J, Ma CB, Woo SL. Biomechanical analysis of a posterior cruciate ligament reconstruction. Deficiency of the posterolateral structures as a cause of graft failure. Am J Sports Med. 2000;28:32-9.

4. LaPrade RF, Münch C, Wentorf F, Lewis JL. The effect of injury to the posterolateral structures of the knee on force in a posterior cruciate ligament graft: a biomechanical study. Am J Sports Med. 2002;30:2338.

5. Sidles JA, Larson RV, Garbini JL, Downey DL, Matsen FA $3^{\text {rd }}$. Ligament length relationships in the moving knee. J Orthop Res. 1988;6:593610 .

6. Lee MC, Park YK, Lee SH, Jo H, Seong SC. Posterolateral reconstruction using split Achilles tendon allograft. Arthroscopy. 2003;19:1043-9.

7. Seebacher JR, Inglis AE, Marshall JL, Warren RF. The structure of the posterolateral aspect of the knee. J Bone Joint Surg Am. 1982;64:53641.

8. Wroble RR, Grood ES, Cummings JS, Henderson JM, Noyes FR. The role of the lateral extra articular restraints in the anterior cruciate ligament - deficient knee. Am J Sports Med. 1993;21:257-62.

9. Maynard MJ, Deng X, Wickiewicz TL, Warren RF. The popliteofibular ligament. Rediscovery of a key element in posterolateral stability. Am J Sports Med. 1996;24:311-6.
10. Veltri DM, Deng XH, Torzilli PA, Maynard MJ, Warren RF. The role of the popliteofibular ligament in stability of the human knee. A biomechanical study. Am J Sports Med. 1996;24:19-27.

11. Kannus P. Nonoperative treatment of grade II and III sprains of the lateral ligament compartment of the knee. Am J Sports Med. 1989;17:838 .

12. Covey DC. Injuries of the posterolateral corner of the knee. J Bone Joint Surg Am. 2001;83:106-18.

13. Clancy WGY. Repair and reconstruction of the posterior cruciate ligament. In: Chapman MW. Operative orthopedics. Philadelphia: JB Lippincott; 1988. v. 3. p. 1651-5.

14. Bousquet G, Charmion L, Passot JP, Girardin P, Relave M, Gazielly D. [Stabilization of the external condyle of the knee in chronic anterior laxity. Importance of the popliteal muscle]. Rev Chir Orthop Reparatrice Appar Mot. 1986;72:427-34. French.

15. Müller W. Die rotations instabilitat am kniegelenk. Hefte Zur Unfallheilkunde. 1990;125:51-68.

16. Veltri DM, Warren RF. Operative treatment of posterolateral instability of the knee. Clin Sports Med. 1994;13:615-27.

17. Shahane SA, Ibbotson C, Strachan R, Bickerstaff DR. The popliteofibular ligament. An anatomical study of the posterolateral corner of the knee. J Bone Joint Surg Br. 1999; 81:636-42.

18. Latimer HA, Tibone JE, Elattrache NS, McMahon PJ. Reconstruction of the lateral collateral ligament of the knee with patellar tendon allograft. Report of a new technique in combined ligament injuries. Am J Sports Med. 1998;26:656-62.

19. Noyes FR, Barber-Westin SD. Surgical reconstruction of severe chronic posterolateral complex injuries of the knee using allograft tissues. Am J Sports Med. 1995;23:2-12. 